\title{
MARKETING MIX MODELING FOR PHARMACEUTICAL COMPANIES ON THE BASIS OF DATA SCIENCE TECHNOLOGIES
}

\author{
Galyna Chornous ${ }^{1}$, Yana Fareniuk ${ }^{2}$ \\ ${ }^{1,2}$ Taras Shevchenko National University of Kyiv, Kyiv, Ukraine \\ e-mails: ${ }^{1}$ chornous@univ.kiev.ua, ${ }^{2} y$ fareniuk@gmail.com
}

Received: 01 July 2021; Accepted: 20 August 2021; Online Published: 26 August 2021

\begin{abstract}
The article contains the results of Data Science technologies application (including machine learning and regression analysis) to modelling the results of marketing activities of key brand of one of the Ukrainian pharmaceutical companies on the basis of historical data for the period from 2015 to 2019 in weekly detail. The main goal of research is to estimate the influence of key elements of the marketing mix (penetration of pharmacy chains, price policy vs main competitors, advertising activity of the brand and its competitors in all communication channels (television, Digital, radio, outdoor advertising, press)) on company's sales, volume market share and value market share in relevant segment of drugs. Based on the results obtained, the article explains in detail the impact of penetration, price policy and media activity on the competitiveness of the enterprise and its position in the market. The influence of the price policy and penetration directly on sales (market share), as well as on other factors (including the effectiveness of the brand's advertising activity on television) is estimated and taken into account for development the effective marketing strategy. Based on the research, the article contains main recommendations for optimizing the marketing strategy to maximize the company's sales and increasing market share in monetary or physical terms. Data Science technologies become a tool for sales management, because it creates the ability to quantify the impact of each factor on sales, determine their optimal combination for achievement of business goals and strengthening the company's position in the market, effective marketing budgets distribution and scenario forecasting. Continuous model support allows to increase the return on each factor, improve return on investment and ensure the achievement of business goals in the most efficient way. Data Science forms the basis for finding effective marketing solutions and forming an effective business development strategy.
\end{abstract}

Keywords: marketing mix modelling, data science, machine learning, regression analysis, pharmaceutical company, Return on investment (ROI), strategy

JEL classification: $\mathrm{C} 5, \mathrm{M} 3, \mathrm{O} 1$

Citation:

Chornous, G., Fareniuk, Y. (2021). Marketing mix modeling for pharmaceutical companies on the basis of data science technologies. Access to science, business, innovation in digital economy, ACCESS Press, 2(3): $274-289$. https://doi.org/10.46656/access.2021.2.3(6)

\section{INTRODUCTION: MARKET CONTEXT AND BUSINESS TASKS}

The current business environment of enterprises is quite competitive and requires companies to focus on effective business activities with sufficient profitability. Establishing an effective marketing mix in accordance to its relationship with business results (fair and reasonable price, necessary penetration level and relevant media presence) is given considerable attention in modern marketing. Pricing is an important element of a modern marketing mix of any enterprise, where the main focus is on finding the optimal market price that will satisfy both the company and the consumer (Zhukov et al., 2014). Media activity is one of the key channels 
for attracting of new audience for a brand which helps sales increase and improving of companies' position on the market. High competition in the market and high inflation in the media create the need to find progressive solutions, and Data Science opens up many opportunities in this direction at all management level (operational and tactical tasks and strategic decisions). Own data approaches that combine Data Science technologies, marketing technologies and comprehensive expertise will be the most valuable resources for optimizing marketing investments and differentiating firms on the market.

The pharmaceutical business is one of the quickly growing in Ukraine. The sales volume of all categories of goods in the "pharmacy basket" amounted to UAH 74.3 billion ( 2.8 billion USD) in 9 months in 2019 and increased by $15.9 \%$ in hryvnia and $18.3 \%$ in dollar compared to the same period in 2018. In physical terms, sales amounted to 1.25 billion packages and dropped by $3.1 \%$.

The pharmaceutical market in Ukraine is developing mainly due to rising prices (high inflation component), as well as due to the redistribution of consumption towards more expensive drugs (substitution index), as evidenced by the dynamics of the drug market indicators in monetary terms.

At the same time, inflation in the pharmaceutical industry and in healthcare in general, according to the State Statistics Service of Ukraine is still lower than in the country in general and in other categories of goods and services.

The weighted average cost of 1 package for 9 months of 2019 amounted to UAH 58.7 and increased due to inflation by 19.6\% compared to the same period in 2018 (Kirsanov, 2019b). Under such conditions, rising prices are partially offset by increasing consumer incomes, as market development depends largely on the consumer and his level of well-being. In recent years, there has been an increase in both wages and incomes. The National Bank of Ukraine is constantly recording wage growth, but its growth rate is slowing down. According to the results of the second quarter of 2019, the State Statistics Service of Ukraine reports an increase in real incomes of the population by $7 \%$, and nominal - by $17 \%$.

The improvement of the economic situation in the country has positive influence on the development of the pharmaceutical industry: 2019 is characterized by double-digit growth in sales of "pharmacy basket" goods in hryvnia and dollar equivalent, although they slowed down compared to the previous year. According to the latest estimates and predictions of experts, the development of the pharmaceutical industry will continue, despite the impact of the COVID-19 crisis.

With the rapid development of the pharmaceutical market and solving the problems related to the economic crisis, in order to improve the management system of business competitiveness, the mechanism of managing the elements of the marketing mix is becoming increasingly important to improve business performance and maximize profits.

Pricing and media strategies in the marketing system occupy one of the key places (Korzh, 2018; De Toni et al.). They are an integral part of marketing strategies, and there is significant potential for optimization for companies that are deeply analyse the marketing data to find effective solutions and enhance their competitive advantage. 
To make informed business decisions about choosing an effective marketing strategy, it is advisable to develop it using a systematic approach that allows the company to succeed in the market. According to this, there is an urgent need to improve the marketing strategy and mechanisms for managing its elements, and Data Science technologies are the tools that open up significant opportunities in this area.

\section{MATERIALS AND METHODOLOGY}

A large number of articles have been written on this topic. Marketing mix modelling (MMM) is the most commonly used method, which consists of building a regression model based on historical data to present business metrics (sales or share of market) as a function of marketing and advertising variables, such as price index, product characteristics, media activity (number of advertising outputs, ratings, impressions) and other variables such as seasonality, macroeconomic factors, weather, level of competition in the market and so on.

The theoretical foundations and a wide range of issues related to the modelling of socio-economic processes are reflected in the works of such domestic and foreign scientists as Ansoff I., Kotler F., Porter M., Thompson A., Kizim M. (Kizim et al., 2009), Pushkar O., Ponomarenko V., Klebanova T. (Ponomarenko et al., 2020), Blagun I., Chernyak O., Khristianovsky V., Vitlinsky V. (Ponomarenko et al., 2013), Tarasevich V. (2010) and many others.

The greatest research of the theoretical and practical issues of marketing pricing policy was found in the works of Balabanova L., Osypenko S., Romanchyk T. (Osypenko et al., 2020), Slushaenko N. (2015), Myshko O. and Kaminska I. (Myshko et al., 2021), Noritsyna N. (2007), Farm A. (2020), which focused on the relationship between price and competitiveness. The importance of this aspect of marketing for any enterprise was showed by De Toni D., Milan G. (De Toni et al., 2017), Ryzhikov V., Pankov V. (Ryzhikov et al, 2004).

The researches of the application of machine learning technologies and Data Science for modelling the enterprises' marketing mix were conducted by such domestic and foreign scientists as Bazhenov Y., Burnet J., Bodnar L., Vinkovska A. (Vinkovska et al., 2019), Büschken J. (2007), Guz M., Lysenko Y., Lukyanets T., Bowman D. and Gatignon H. (Bowman et al., 2010), Pargelova A. (Pargelova et al., 2010), Rossiter J. (Rossiter et al., 2017), Romat E., Batra R. (Batra et al, 2016), Fryburger V., Sandage C. (Sandage et al, 1986) and others.

Data Science and mathematical modelling open up significant opportunities in the implementation of marketing activities of any company. Chan and Perry (2017) argue the importance for companies to work with different approaches to marketing modelling, as advertisers need to understand the effectiveness of their media and marketing spends in driving sales to optimize the distribution of marketing budgets.

The contribution of classic machine learning methods like regression analysis to marketing decisionmaking is quite important, but there are alternative methods. Dawes et al. (2018) research evidence-based methods that have been shown to be useful for forecasting. Jin et al. (2017), Zhang and Vaver (2017) recommend using Bayesian hierarchical modelling. 
According to research Chan and Perry (2017), the potential of marketing mix modelling may be limited by the lack of detailed and qualitative data. To solve this problem, they propose to develop better data and models, as well as test them, using simulations as the main instruments of improvement for marketing mix modelling.

Despite the scientific achievements of various scientists, many issues of finding ways to optimize marketing strategy remain unresolved. Elements of the marketing mix in the marketing system are well studied, but the optimization of the marketing mechanism and forecasting the results of marketing activities depending on marketing factors requires more detailed research. After all, an effective marketing strategy (including pricing policy and media strategy), as well as improving the mechanism of distribution of marketing budgets and effective implementation of marketing activities are determinants of sales growth of any enterprise (Zhukov et al., 2014). Adaptation of marketing strategy in highly competitive industries is one of the areas of daily work of every pharmaceutical campaign in Ukraine and in the world. Therefore, finding a solution to this issue based on data is extremely important.

The goal of the research is to modelling the impact of marketing mix elements on sales of key brand of one of the Ukrainian pharmaceutical companies based on Data Science and machine learning technologies (regression analysis), as well as the formation of recommendations for improving the efficiency of the marketing activities of companies in pharmaceutical business and optimizing the marketing results depending on the chosen marketing strategy of a particular product.

To achieve this goal were used economic and mathematical modelling (including on the basis of machine learning technologies like regression analysis) of the dependence of sales (market share in volume and in value) of certain drugs on the following factors: penetration of pharmacy networks (pharmacy coverage and drug availability for consumers), pricing policy (the index of the drug's price compared to brand's competitors), media activity of the brand and its competitors in all communication channels (television, Internet, radio, press and outdoor advertising), recommendations of doctors and pharmacists and others. Pharmaceutical companies have specific marketing mix (compared to Fast Moving Consumer Goods (FMCG) market) as include work with doctors and pharmacists and realisation of necessary penetration of pharmacy network.

Data on all variables for the period from 2015 to 2019 were collected in a weekly breakdown for all drugs in the relevant category (database was collected on the basis of data of the pharmaceutical company from Proxima Research, as well as the Industrial Television Committee and Nielsen Ukraine). Due to confidentiality, all data in the article will be indexed from 0 to 1.

For the constructed multiple regression models, which were estimated by the method of least squares, hypotheses about the adequacy of the models, the significance of the coefficients, the presence of heteroskedasticity and autocorrelation were tested.

Also, for the development of recommendations for optimal pricing policy, an approach based on machine learning technologies (coefficients from regression models and additional calculations) was developed to determine the optimal range of price index (price of drug compared to the average price of competitors) to maximize market share in packaging or market share in value depending on the company's goals. Determining 
the influence of media factors helps to formulate recommendations for media strategy of this drugs and as a result increase ROI (return on investment) of media investments.

\section{RESULTS AND DISCUSSION}

\subsection{Data Science as a relevant tool to find effective business solution}

The significant level of competition in the pharmaceutical industry, the growth in the price of advertising activity and the desire of manufacturers to constantly increase sales generates the need to find effective marketing solutions. To achieve these goals, it is necessary to actively use the data available on the market, using machine learning technologies and Data Mining approaches. Data Science is an extremely effective tool for improving the effectiveness of marketing activities of pharmaceutical companies, its optimization and greater validity.

The research of marketing activities of several pharmaceutical brands in Ukraine in one product category will show how on the basis of economic-mathematical modelling (regression analysis) and other Data Science technologies we can analyse what factors and to what extent affect the business results of the company (sales or market share in the relevant category). Understanding the influenced factors enables to calculate the elasticity of sales to each factor and as a result to distinguish the optimal range for each of them taking into account their marginal utility (for example, calculating price elasticity and finding the optimal value of the price index - the ratio of brand price and average price of competitors or determining the optimal level of media pressure in each communication channel). In addition, understanding the effectiveness of each communication channel make it possible to develop an effective media strategy and tactics for the brand.

Project was deploying in accordance with the most widely-used analytics model named "Cross-Industry Standard Process for Data Mining" (CRISP-DM) (Brown, 2015; Shearer, 2000). CRISP-DM describes the process through 6 stages: "Business Understanding, Data Understanding, Data Preparation, Modelling, Evaluation and Deployment" (Chernyak et al., 2014). In this project, the overall process was implemented through step-by-step analysis and modelling, as shown in Fig.1.

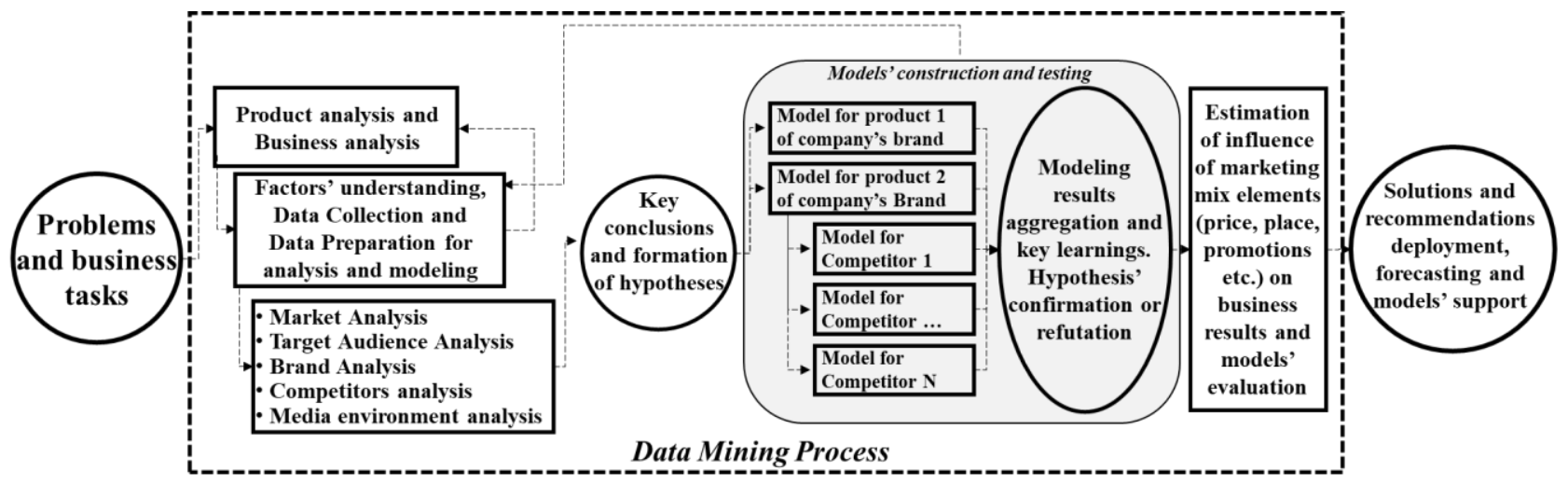

Fig. 1. Proposed concept of modelling marketing mix project realization

Source: Developed by the authors 
The process includes the ability to flexibly change the order of the stages, going back when the need arises. Data mining is cyclical in nature, as the process of finding solutions continues throughout the project and after the project has been deployed. The main knowledge, learnings and experience of the previous cycle can create new, deeper business issues that have a positive impact on future data mining processes (Chernyak et al., 2014).

At the first stage of working with a business task, it is necessary to study in detail the features of the brand and the category for which the analysis is implemented to determine all the factors that influence on the final performance of the business. In this study, we examine a brand that is a leader in the category, but is gradually losing its market position in favor of competitors who have active media support on television, as well as actively working with doctors and pharmacists.

In addition, a feature of this category is the availability for the consumer of two forms of the drug - drops or syrup (liquid form) and capsules or tablets (solid form), so in the future when using Data Science and machine learning to model volume market share (SOM - share of market) will consider a separate model for liquid and solid forms of drug (Fig. 2).

Economic and mathematical modelling of marketing mix on the basis of Data Science technologies enables to:

- determine the factors that influence on sales, as well as the extent of this impact;

- evaluate the elasticity of sales for each factor;

- forecast the target metrics depending on the planned level of each factor;

- make recommendations on the optimal / necessary level of each factor to achieve the business goals;

- compare the impact of factors for the company's brand and for competing brands in the case of model building for other brands also.

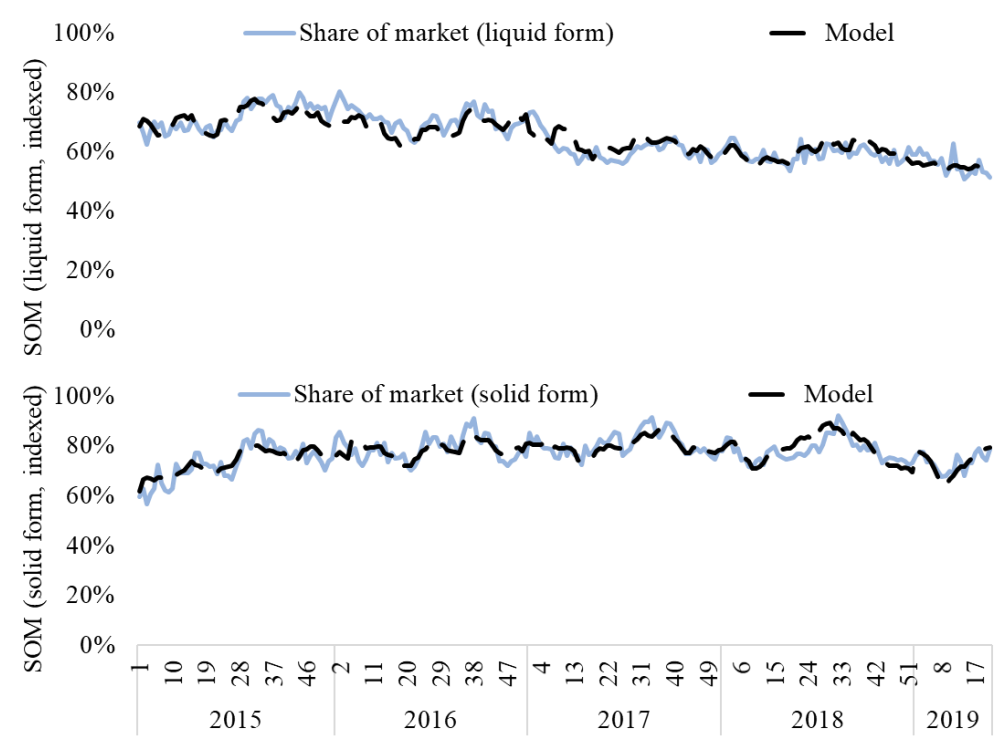

Fig. 2. Models for liquid and solid forms of the drug

Source: Authors' calculations based on data of the pharmaceutical company from Proxima Research, as well as the Industrial Television Committee and Nielsen Ukraine (data indexed due to confidentiality) 


\subsection{Marketing Mix Modelling results}

The key factors influencing the level of drug sales and its market share included the following:

- organic level (base line of sales - set of macroeconomic and rational marketing factors);

- penetration (distribution) - percentage of pharmacy stores in which the drug is available for consumers, the level of coverage of pharmacies;

- $\quad$ price policy - price index in comparison to brand's competitors (the ratio of the price of the drug and the average market price for similar products on the market);

- pharmacists' recommendations;

- doctors' recommendations;

- advertising activity of competitors in terms of communication channels, creative materials, video durations, etc.;

- media activity of brand in terms of communication channels, creative materials, video durations, etc.

The evaluation of influence of these factors on the basis of machine learning technologies (regression analysis) creates the basis for business optimization and finding effective marketing and media solutions and as a result development an effective strategy for the company's growth in the future.

The main criteria for model optimization are increasing of $\mathrm{R}^{2}$, its adequacy, absence of autocorrelation and heteroskedasticity and opportunities to estimate the efficiency of marketing mix elements with high level of significance.

The optimal model for each form of drug is multiple regression model and looks like this:

SOM $=$ Constant $+a_{1} *$ Penetration ${ }_{1}+a_{2} *$ Penetration $_{2}+a_{3} *$ Price_index $+a_{4} *$ Doctors + $+a_{5} *$ Pharmacists $+a_{6} *$ Adstock $\left(T V_{1}\right)+a_{7} * A d s t o c k\left(T V_{2}\right)+\ldots+a_{n} * \operatorname{Adstock}\left(T V_{n}\right)+b_{1} *$

$*$ Adstock $\left(T V_{-}\right.$Competitor $\left.{ }_{1}\right)+b_{2} * A d s t o c k\left(T V_{-}\right.$Competitor $\left._{2}\right)+\ldots+b_{m} * A d s t o c k\left(T V_{-}\right.$Competitor $\left.{ }_{m}\right)$, where (1)

- $\quad S O M$ - share of market in Volume;

- $\quad$ Penetration $_{1}$ and Penetration $_{2}$ - penetration level for SKU 1 and SKU 2 respectively;

- Doctors or Pharmacists - level of brand's recommendations by doctors and pharmacists;

- $T V_{l}$ or $T V_{2}$ or $T V_{n}$ - television activity of brand by different creative materials $\left(T V_{l}\right.$ is for creative 1 and $T V_{n}$ is for creative $n$ respectively);

- TV_Competitor or TV_Competitor $_{m}$ - TV activity of competitor 1 or competitor 2 respectively;

- Adstock is the instant, prolonged and lagged effect of advertising activity on consumer purchase behavior, which indicate influence of television activity during a time.

$$
\operatorname{Adstock}(T V) t=T V t+a * \operatorname{Adstock}(T V) t-1
$$

The built models are characterized by high quality indicators (coefficients of determination $\mathrm{R}^{2}$ are $78 \%$ and $70 \%$, respectively for model for liquid form and for model for solid form), and the average error RMSPE is less than $4 \%$, the models are adequate, all factors are significant, the both models haven't autocorrelation and 
heteroskedasticity), which confirms their practical application for optimization of marketing activities (Table $1)$.

Table 1. Technical Characteristics of One of the Models (for one of the Product Form)

\begin{tabular}{lcccc}
\hline \multicolumn{1}{c}{ Indicator } & Coefficient & $\begin{array}{c}\text { Stand. } \\
\text { Error }\end{array}$ & t-statistics & P-value \\
\hline Constant & 0,120 & 0,00 & 71,77 & 0,0000 \\
Penetration & 0,983 & 0,12 & 8,24 & 0,0000 \\
Price index & $-0,970$ & 0,09 & 11,02 & 0,0000 \\
Doctors & 0,561 & 0,41 & 1,37 & 0,0000 \\
Pharmacists & 0,396 & 0,11 & 3,57 & 0,0000 \\
TV & 1,085 & 0,18 & 6,03 & 0,0000 \\
Competitors & 0,988 & 0,14 & 7,23 & 0,0000 \\
Multiple $\mathrm{R}^{2}$ & 0,78 & & Adjusted $\mathrm{R}^{2}$ & 0,77 \\
F-statistics & 140,93 & & p-value & 0,0000 \\
\hline
\end{tabular}

Source: Own calculations based on data of the pharmaceutical company from Proxima Research, as well as the Industrial Television Committee and Nielsen Ukraine (data indexed due to confidentiality)

The base level of sales or share of market (constant in Table 1) is the level of company's sales that will accumulate in the short term with a minimum level of penetration level (level of presence in pharmacy stores), a minimum level of price index compared to competitors, minimal level of doctors' and pharmacists' recommendations and in conditions of lack of advertising activity of the brand for which prepared analytics, and competing brands, and includes a number of other qualitative characteristics.

The period of drug's presence on the market influenced the share of the base line impact on sales or share of market and it will range from the minimum level to most of the sales of the drug. So, if the drug is on the market in the last few years and we prepare analytics from the moment of its launch, the base line will be absent and vice versa - if the drug is on the market in the last 5 years or more, the share of the base line will be growth.

On the case of this brand, the base line generates a significant share of sales $-57 \%$, but this factor is stable in the short term (is a constant in the model), so the right work with other factors creates opportunities for the brand for future growth (Fig. 3).

In order to estimate the influence of each factor on sales, it is necessary to analyse in detail the dynamics of each of them, distinguish their impact through the construction of models, as well as compare all factors' parameters with indicators for competing brands on the market.

Factor 2 - penetration level. In general, the high level of penetration is an integral part of effective brand growth, because the presence on the shelf is a key marketing factor not only for pharmaceutical companies, but also for all FMCG brands. This brand is one of the main brands in the pharmaceutical market and in 2019 provided a high level of penetration for the main product form - up to $90 \%$, actively increasing it in previous years. Growth of penetration during the previous periods generated a significant additional growth in sales of brand and its position on the market.

Factor 3 and 4 - recommendations of doctors and pharmacists. Doctors and pharmacists are one of the main communication channels with the potential consumers, as they often make the final decision for purchase after 
a doctor's recommendation or pharmacist's advice. As a result, the proper level of work with these medical personnel are a necessary condition for the effective development of the brand and the company in the market in general. Of course, stimulation the level of doctors' and pharmacists' recommendations, even at a low level, provides a growth in the company's sales, and its strengthening improves the company's efficiency and its sales level. Thus, changes in work with doctors and pharmacists provided additional sales growth of our brand and generated X packages for the period 2015-2019.

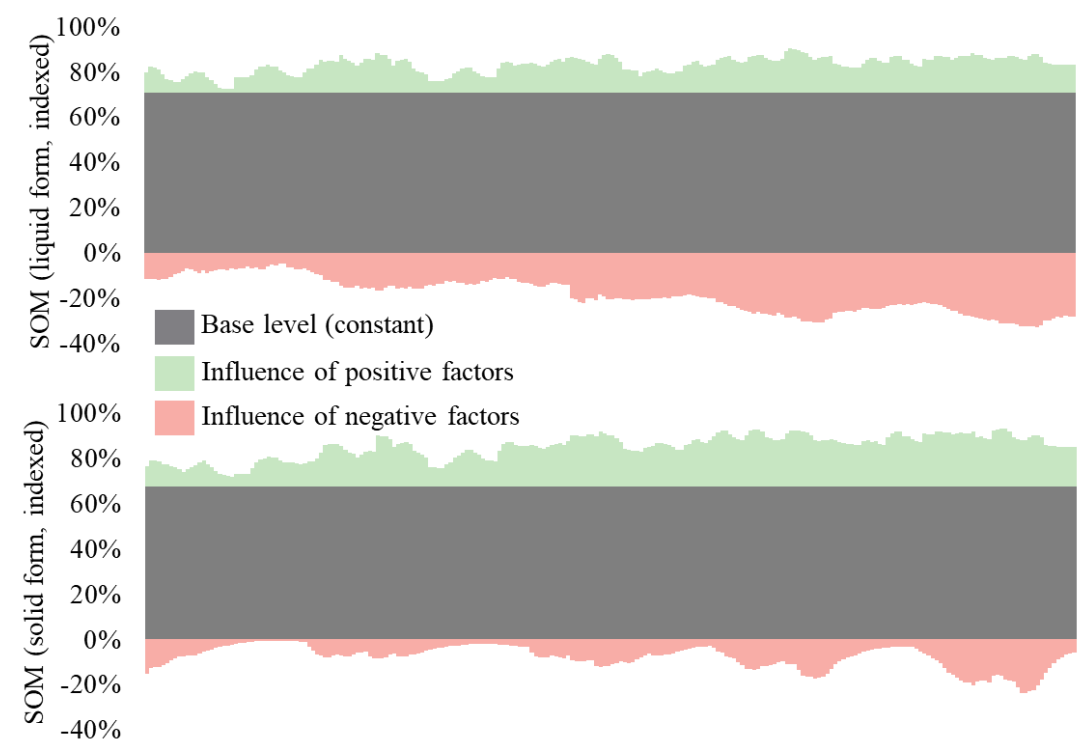

Fig. 3. Model decomposition by different group of factors (base line, positive factors, negative factors)

Source: Authors' calculations based on data of the pharmaceutical company from Proxima Research, as well as the Industrial Television Committee and Nielsen Ukraine (data indexed due to confidentiality)

Factor 5 - price policy. In the period 2015-2019, the company raised price for this brand faster than its competitors, which stimulated to an increase in the price index (the ratio of the price of the drug compared to average price on the market). The average price level of the drug is $5-25 \%$ higher than the competitors' price, depending on the products' segment, which have negative effects on the dynamics of sales in physical term.

Ukrainians are a nation that tends to save, so rising prices faster than competitors leads to switching to competing brands and losing brand's market share in physical term. As a result, changes in the pricing index in previous periods led to a loss of brand sales (Fig. 4).

However, if we analyse the pricing policy, a certain level of price growth might lead to a drop in sales in physical terms, but generate an additional level of revenue when the price increase compensates for the fall in sales in physical terms and vice versa - a significant growth in prices of drug might lead to a significant drop in sales in physical terms and the company's profit will be significantly reduced. As a result, there is potential for optimization depending on the price elasticity of sales and share of market in value and in volume.

Taking into account the business goals - to increase share of market in value (increase revenue) or increase share of market in volume (increase penetration of drug among target audience and consumers), recommendations for price policy will be radically different. 


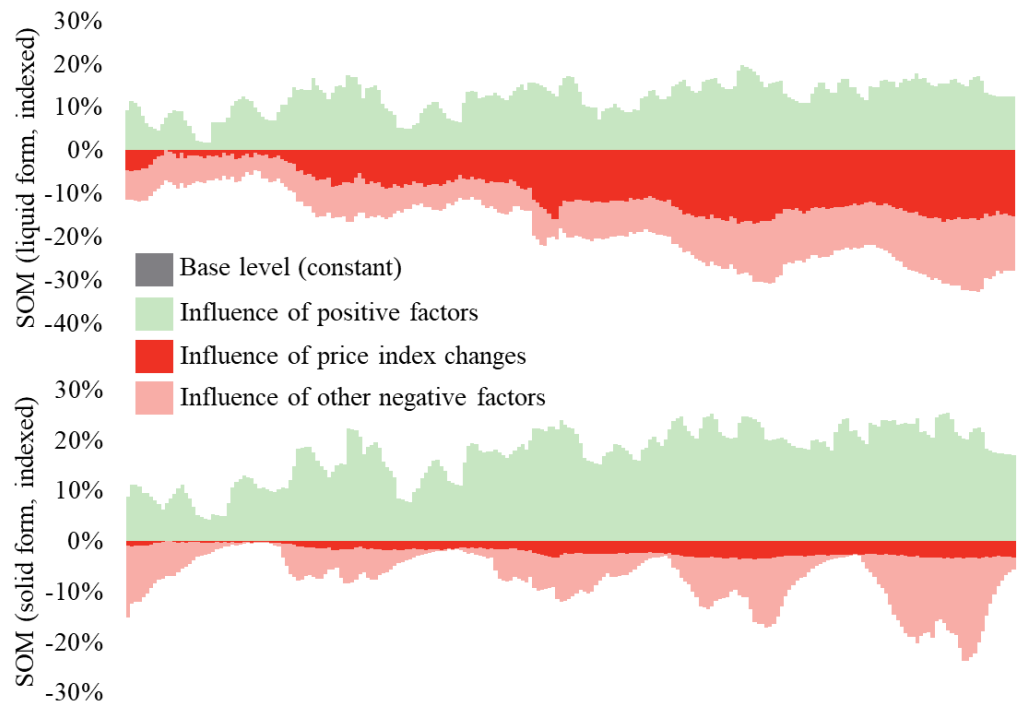

Fig. 4. The impact of price on market share in the dynamics of 2015-2019 (model decomposition)

Source: Authors' calculations based on data of the pharmaceutical company from Proxima Research, as well as the Industrial Television Committee and Nielsen Ukraine (data indexed due to confidentiality)

On the basis of the built econometric models for liquid and solid forms of the drug, we can estimate the curves of share of market in money and share of market in packages depending on the price index level, as the coefficients of models at the price index indicate how share of market will change with rising price index by 1 unit (the character of the connection is linear in the case of building a linear regression or non-linear in another conditions).

The share of market in value and the share of market in volume are linked by a price index. Due to the fact that the rate of change of share of market in physical terms does not coincide with the rate of change of the price index, there is a non-linear relationship between the price index and share of market in value, which leads to an optimization zone depending on business objectives.

On the case of our brand of drug, the optimal value of the price index to maximize share of market in money was from 1.0 to 1.4 (Fig. 5), which means that the drug should have parity prices to the market or be more expensive up to $+40 \%$ to average prices on the market to obtain the maximum level of profit. Depending on the business' goals, this methodology becomes a flexible and convenient tool for the price policy department, as it is possible to form a recommendation for price level to achieve the goals of both share of market in value and share of market in volume.

Factor 6 and 7 - advertising activity of the brand and its competitors. One of the main factors in increasing sales is the active promotion of brands through media channels, because advertising is the key way of communication between producers and their consumers.

The Ukrainian pharmaceutical market continues to develop actively, but it is highly competitive, and in the struggle for the consumer, companies are forced to actively promote their brands via advertising activity. 


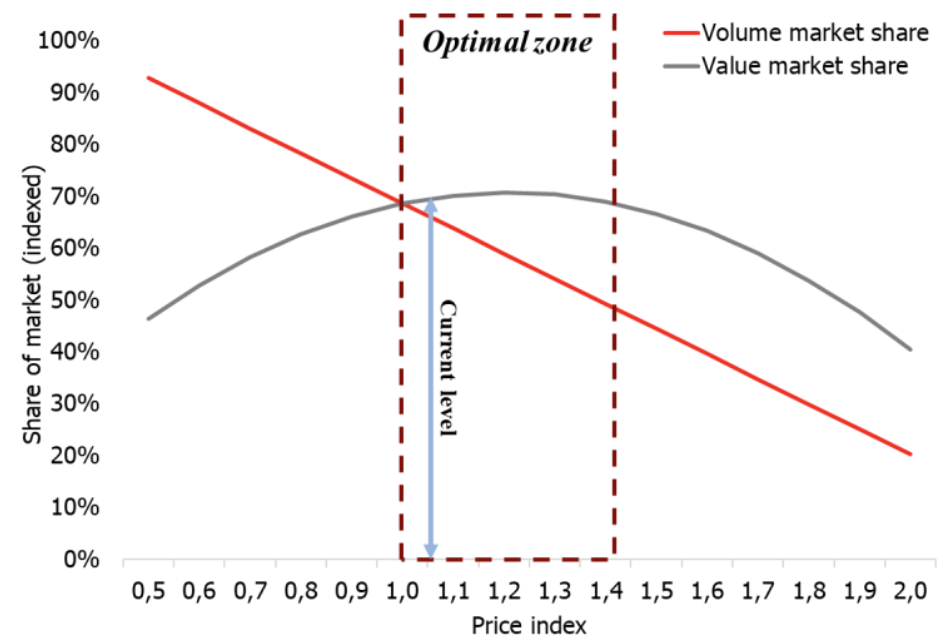

Fig. 5. Optimal level of price index in terms of growth of value market share

Source: Authors' calculations based on data of the pharmaceutical company from Proxima Research, as well as the Industrial

Television Committee and Nielsen Ukraine (data indexed due to confidentiality)

The main channel for the advertising activity of pharmaceutical manufacturers has long and stable been television (TV). All-Ukrainian Advertising Coalition (VRK), estimated that in 2019 the volume of the TV advertising market (direct advertising and sponsorship) increased by $24 \%$ and amounted to UAH 11.5 billion, which corresponds to about $47 \%$ of the total volume of advertising media market of Ukraine in 2019.

Pharmaceutical companies are one of the main advertisers on Ukrainian TV. The share of their investments in TV consistently occupies about $30 \%$ of the total advertising investment in this communication channel. They invested more than UAH 2.1 billion in their brand's advertising on TV in 9 months in 2019, increasing their media budgets by $28 \%$ compared to the same period in previous year. Investments in TV advertising by pharmaceutical companies show a steady increase, but the volume of activity by EqTRPs (weighted target rating points) has been dropping in recent years due to significant inflation.

The efficiency of investment in advertising is determined by the indicators of EqTRPs, which ultimately affect the company's sales as this indicator is relevant to advertising cost. Due to the increasing of advertising instruments' cost due to high inflation, among pharmaceutical companies created the significant preconditions for finding effective data-based solutions on the basis of in-depth analysis of all available data on the market using Data Science technologies to optimize marketing (including media) investments.

TV support generates the growth of the brand's share of market, but the TV activity of competitors has a significant negative impact. Realizing the significant negative influence of TV activity of competitors, it is important to control share of voice (SOV) on TV in the future and realize parity placement with competitors, because the more advertising activity a brand launches during the year, the higher sales level it stimulates. The loss of share of voice on TV is the main reason for the loss of the brand's position in the market for this brand.

It should be noted that the efficiency of TV activity differs during the year due to the seasonality of the category and price conditions of TV instruments, which necessitates a redistribution of TV activity during the year to get the maximum return on investment (ROI) and as a result increase sales level. In this category, sales 
are reduced in the summer, due to the specifics of the disease and, accordingly, treatment, but the prices for TV advertising in this period are also slightly lower. Autumn and spring - the main sales season, but the cost of advertising increases significantly during this period. As a result, the ratio of these indicators will determine the effectiveness of media activity and, as a consequence, the feasibility of its launch in each period of time. Given the results obtained for this brand, it is most appropriate to use TV advertising almost throughout the year, except for the period April-May, when lower advertising costs do not offset the decline in sales level and as a result the effectiveness of media activity declines significantly (Fig. 6).

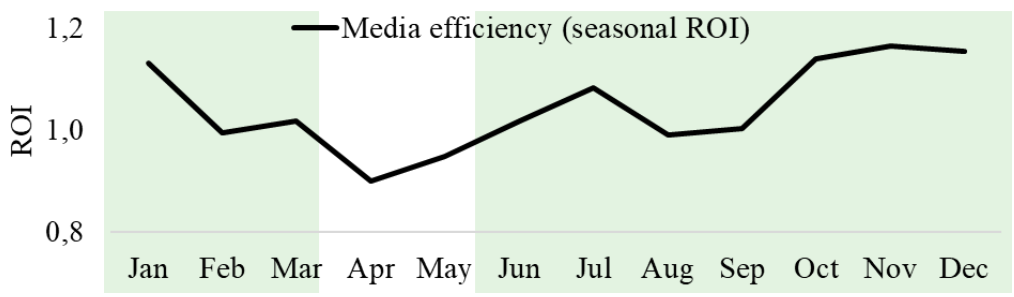

Fig. 6. Response from TV activity during a year

Source: Authors' calculations based on data of the pharmaceutical company from Proxima Research, as well as the Industrial Television Committee and Nielsen Ukraine (data indexed due to confidentiality)

The effectiveness of advertising activity depends on a large number of factors, both media (average weekly pressure, periods of activity, creative materials, videos' duration, etc.) and non-media (including penetration and price policy). To test these hypotheses, similar economic and mathematical models were constructed for other brands in this category. After that, the results of all models were aggregated and the following conclusions were proved:

- The hypothesis that more weekly pressure (more activity) provides higher efficiency of media presence and as a result a higher level of sales is generated due to advertising activity was refuted. Within this category, we identified brands that realized a presence on TV with high weekly weights (AWW average weekly weights), which did not provide a corresponding increase in business performance (the brand in this case overinvests). As a result, recommendations were formed regarding the optimal range of activity to obtain the maximum level of ROI - from 150 to 200 TRPs (target rating points) per week (Fig. 7).

- The influence of penetration on the effectiveness of advertising activity: the lower the penetration of pharmacies, the lower the efficiency of TV support, because the target audience, coming to the pharmacy stores can't buy the drug due to its absence. The product for which the analysis and modelling were prepared has a high penetration level (more than 90\%), which has a strong positive effect on the efficiency of TV activity.

- The influence of price index on effectiveness of media support is opposite, but also quite significant: the higher the price of the product, the fewer interested audience dare to buy, because the level of price in these conditions become a barrier for the consumer and as a result efficiency from TV activity reduce (Fig. 8). The brand for which the analysis was prepared is in the middle price group and has 
sufficient efficiency from TV activity. The optimal level of the price index to maximize sales of the brand is $1.0-1.4$ (Fig. 5).

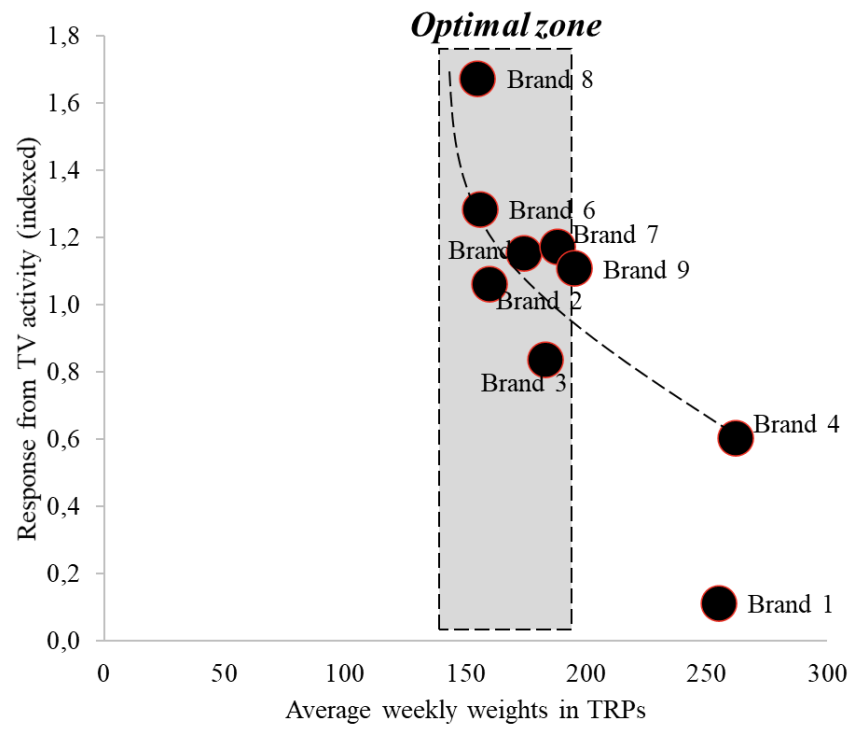

Fig. 7. The impact of average weekly weights on efficiency of media support and optimal range for media pressure Source: Authors' calculations based on data of the pharmaceutical company from Proxima Research, as well as the Industrial Television Committee and Nielsen Ukraine (data indexed due to confidentiality)

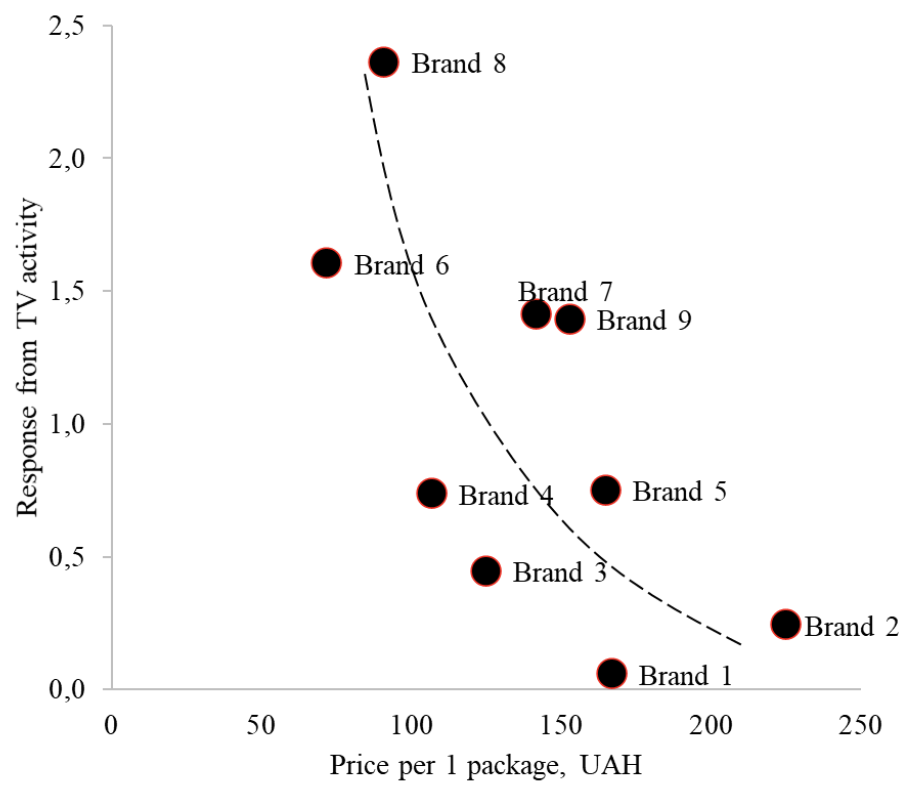

Fig. 8. The impact of price on efficiency of media support

Source: Authors' calculations based on data of the pharmaceutical company from Proxima Research, as well as the Industrial Television Committee and Nielsen Ukraine (data indexed due to confidentiality)

It is important to understand that these recommendations and conclusions can't be taken generally for all brands and companies on the market, as the final business results are a complicated combination of many factors and conditions that are formed at each time, which requires an individual approach and analysis in each situation. 


\section{CONCLUSION}

Thus, the economic and mathematical model enables to understand and estimate the contribution of each marketing factor in the brand's sales level and make it possible to form effective recommendations for each element of marketing mix. The econometric model in such conditions is a convenient and flexible tool for marketing management, because it make it possible to find the optimal combination of factors to achieve shortterm and long-term business goals through management of key KPIs (key performance indices). Regular model's support enables to maximize the influence of each factor, which ultimately make it possible to achieve the necessary business results by the minimum budget or higher business results by the current existing budget.

Thus, the modelling and ongoing process of data analysis becomes a convenient tool for making effective operational marketing decisions:

- estimation on a regular basis of the optimal price taking into account the dynamics of competitors' prices and monitoring its effect on sales;

- tracking the efficiency of the advertising campaign in all communication channels;

- forecasting of business results at different scenarios of activity in the communication with the potential consumers due to work with doctors and pharmacists;

- forecasting of business results for different combinations of marketing factors (realizing of scenario forecasting);

- calculation of optimal level of each factor taking into account the marginal efficiency of each of them;

- analysis of the influence of factors on brand sales, evaluation of winnings and losses.

Econometric model for this pharmaceutical brand helps to find following conclusions:

- TV activity is a main driver of sales growth, but efficiency is different by each month and influenced by price policy and distribution level;

- Optimal media pressure per week - 150-200 TRPs (target rating points);

- Competitors' activity has strong negative influence, so we need to control share of voice in communication channels (to have leading position by media pressure);

- Distribution generates a large share of sales, so we need to maintain current level of distribution (at least $90 \%)$;

- Optimal range of price index is 1.0-1.4 (price vs competitors).

The economic and mathematical model acquires the greatest value at the moment when it becomes a tool for business simulations and the opportunity of implementing scenario forecasting. In such case there is a possibility to assess and realize the various scenarios of business development, for example:

- What will happen if we increase TV support by X\% and increase the price by $\mathrm{Y} \%$ ?

- What will happen if we transfer the budget for work with doctors and pharmacists to TV activity? 
- What will happen if we drop prices by $\mathrm{X} \%$ and change the period of media presence from October to September?

Realization of Data Science projects have strong economic influence on business performance as help to increase return on marketing investment by more than $5 \%$ and plan future business results with average error less than $5 \%$.

\section{Conflict of interests}

The authors declare no conflict of interest.

\section{References}

Batra, R., Keller, K. (2016). Integrating marketing communications: New findings, new lessons, and new ideas. Journal of Marketing, 80(6), pp. 122-145. https://doi.org/10.1509/jm.15.0419.

Bowman, D., Gatignon, H. (2010). Market Response and Marketing Mix Models: Trends and Research Opportunities. Foundations and Trends® in Marketing, Vol. 4, No. 3, pp. 129-207. DOI: http://dx.doi.org/10.1561/1700000015.

Brown, M. S. (2015). What IT Needs To Know About The Data Mining Process. Forbes.

Büschken, J. (2007). Determinants of Brand Advertising Efficiency: Evidence from the German Car Market. Journal of Advertising, Vol. 36, No. 3, pp. 51-73. DOI: https://doi.org/10.2753/JOA0091-3367360304.

Chan, D., Perry, M. (2017). Challenges and Opportunities in Media Mix Modeling, Technical report, Google Inc, https://ai.google/research/pubs/pub45998 (accessed: August 2021).

Chernyak, O., Zaharchenko, P. (2014). Data mining: Textbook, Znannya, Kyiv (UA).

Dawes, J., Kennedy, R., Green, K. (2018). Forecasting advertising and media effects on sales: Econometrics and alternatives. International Journal of Market Research, Vol. 60, No. 6, pp. 611-620. DOI: https://doi.org/10.1177/1470785318782871.

De Toni, D., Milan, G., Saciloto, E., Larentis, F. (2017). Pricing strategies and levels and their impact on corporate profitability. Revista de Administração, Vol. 52 (2), p. 120-133. DOI: https://doi.org/10.1016/j.rausp.2016.12.004.

Farm, A. (2020). Pricing in practice in consumer markets. Journal of Post Keynesian Economics, Vol. 43:1, pp. 61-75. DOI: https://doi.org/10.1080/01603477.2019.1616562.

Jin, Y., Wang, Y., Sun, Y., Chan, D., Koehler, J. (2017). Bayesian Methods for Media Mix Modeling with Carryover and Shape Effects, Technical report, Google Inc. https://static.googleusercontent.com/media/ research.google.com/ru//pubs/archive/46001.pdf (accessed: August 2021).

Kirsanov, D. (2019). Advertising of pharmaceutical brands in various media based on the results of 9 months of 2019 Helicopter view. Pharmacy Online, No. 44 (1215), https://www.apteka.ua/article/521815 (accessed: August 2021).

Kirsanov, D. (2019b). Ukrainian pharmacy market for 9 months of 2019: Helicopter View. Pharmacy Online, No. 41 (1212), https://www.apteka.ua/article/519677 (accessed: August 2021).

Kizim, M., Geiman, O. (2009). Scenario modeling of development of social and economic systems: directions, features and mechanisms. Regional economics, №4, pp. 16-23. http://nbuv.gov.ua/UJRN/regek_2009_4_4 (accessed: August 2021).

Korzh, M. (2018). Price optimization modeling in international marketing. Foreign trade: economics, finance, law, №5, pp. 87-100.

Myshko, O., Kaminska, I. (2021). Formation of price policy of trade enterprises in modern conditions. Economy and society, (23). DOI: https://doi.org/10.32782/2524-0072/2021-23-25.

Noritsina, N. (2007). Marketing pricing as a factor of profitable activity of the enterprise. Marketing in Ukraine, №5, pp. $41-43$.

Osypenko, S., Romanchyk, T., Pisarevsky, S. (2020). Substantiating the Prices for Enterprise Products on the Basis of Optimization Models. Business Inform, №6, p. 145-151. https://doi.org/10.32983/2222-4459-2020-6-145-151. 
Pergelova, A., Prior, D., Rialp, J. (2010). Assessing advertising efficiency. Journal of Advertising, Vol. 39/3. DOI: https://doi.org/10.2753/JOA0091-3367390303.

Ponomarenko, V., Klebanova, T., Guryanova, L. (2020). System analysis and modeling of management. BratislavaKharkiv, HSEM - KhNUE im. S. Kuznets, 288 p.

Ponomarenko, V., Klebanova, T., Kizim, O. (2013). Models of Assessment and Analysis of Complex Socio-Economic Systems: Monograph. Kherson, Publishing House "Inzhek", 664 p.

Ryzhikov, V., Pankov V., Rovenska V., Pidgora Y. (2004). Business Economics: Textbook. Kyiv: Slovo Publishing House, $253 \mathrm{p}$.

Rossiter, J., Percy, L. (2017). Methodological Guidelines for Advertising Research. Journal of Advertising, 46 (1), pp. 71-82.

Sandage, C., Fryburger V. (1976). Advertising Theory and Practice. Ninth edition. Homewood, Illinois: Richard D. Irwin, Inc. Journal of Advertising, 5:1, 43, DOI: 10.1080/00913367.1976.10672626.

Shearer, C. (2000). The CRISP-DM model: the new blueprint for data mining. J Data Warehousing, 5:13-22.

Slushaenko, N., Apenko, O. (2015). Modern methods of pricing in the strategic activities planning of pharmaceutical companies in Ukraine. Bulletin of the Taras Shevchenko National University of Kyiv. Economy, Vol. 4, p. 58-63. DOI: http://dx.doi.org/10.17721/1728-2667.2015/169-4/10.

Tarasevich, V. M. (2010). Pricing policy of the enterprise. 3rd ed, Saint-Peterburg, 320 p.

Vinkovska, A., Kiv, A., Koycheva, T., Bodnar, L., Donchev, I. (2019). Information model of the economic efficiency of advertising. SHS Web Conf., 65, p. 1-6. DOI: https://doi.org/10.1051/shsconf/20196504022.

Website of Nielsen Ukraine, https://www.nielsen.com/ua/uk/.

Website of Proxima Research, https://proximaresearch.ua/en/.

Website of State Statistics Service of Ukraine, http://www.ukrstat.gov.ua/.

Website of Television Industry Committee, http://www.itk.ua/en/root/index/.

Website of VRK, https://vrk.org.ua/.

Zhang, S., Vaver, J. (2017). Introduction to the Aggregate Marketing System Simulator, Technical report, Google Inc, https://research.google/pubs/pub45996/ (accessed: August 2021).

Zhukov, S., Fedurtsa, V., Gromova, Y. (2014). Optimization of marketing price policy of industrial enterprises. Actual problems of economy: Scientific economic journal, №6, pp. 213-219.

\section{About the authors}

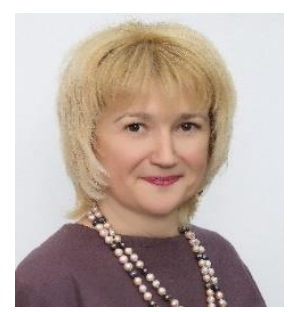

Galyna CHORNOUS, Doctor of Sciences (Economics), Professor of the Department of Economic Cybernetics, Taras Shevchenko National University of Kyiv, Kyiv, Ukraine. Research interests: Decision Support Systems, Economic Cybernetics, Intellectual Data Analysis, Data Science.

ORCID ID: https://orcid.org/0000-0003-4889-1247

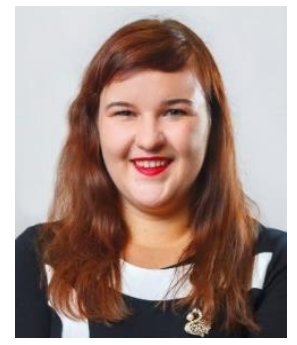

Yana FARENIUK, PhD Student (Economics) of the Department of Economic Cybernetics, Taras Shevchenko National University of Kyiv, Kyiv, Ukraine. The topic of $\mathrm{PhD}$ dissertation is «Modeling of marketing activities of enterprises using Data Science technologies». Research interests: economic and mathematical modeling, mathematical statistics, econometrics, Data Science and Machine Learning in marketing.

ORCID ID: http://orcid.org/0000-0001-6837-5042

Copyright (C 2020 by author(s) and ACCESS Publishing Press This work is licensed under the Creative Commons Attribution International License (CC BY) 